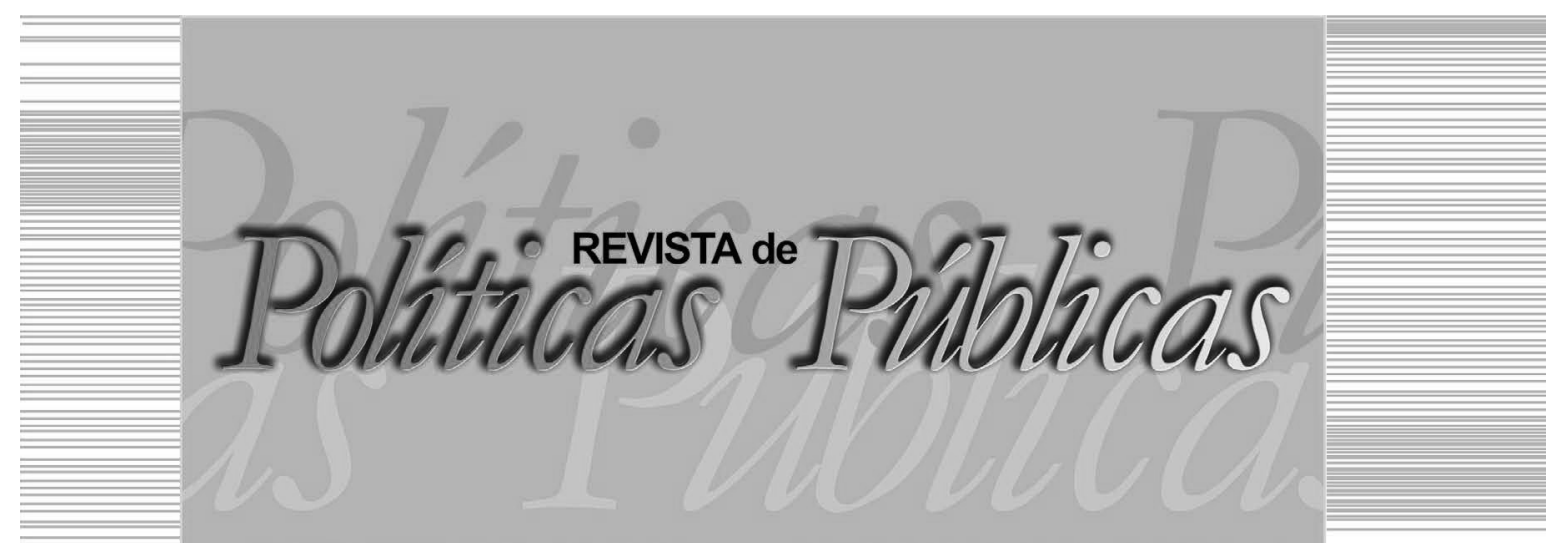

\title{
INOVAÇÃO E EMPREENDEDORISMO À LUZ DE TEORIAS DE POLITICAS PÚBLICAS
}

Tiago Hideki Niwal

\section{Resumo}

A temática que envolve a inovação e o empreendedorismo é recorrente no debate público relacionando-se a políticas econômicas. Desta maneira, o presente artigo procura destacar como essa temática pode servir de elemento explicativo de três teorias de Políticas Públicas, a saber: o advocacy coalition framework; o racionalismo político, e, por fim, o neo-institucionalismo sociológico. Como ilustração do estudo, apresenta-se uma componente empírica, sendo um programa de governo de Portugal, denominado "Programa +e+i", que foi implementado pelo XIX Governo Constitucional de Portugal. Nessa perspectiva, o artigo visa demonstrar a possibilidade de diversas combinações e reflexões em estudos de casos frente ao estado da arte em políticas públicas.

Palavras-chave: Políticas públicas, inovação e empreendedorismo, política econômica.

\section{INNOVATION AND ENTREPRENEURSHIP UNDER PUBLIC POLICIES THEORIES}

\begin{abstract}
The thematic of innovation and entrepreneurship is recurrent in public debate in relation to economic policies. In this way, the present article aims to highlight how this theme can serve as an explanatory element of three theories of Public Policies, namely: the advocacy coalition framework; the political rationalism, and, finally, the sociological neo-institutionalism. As an illustration of Advogado, Doutorando em Políticas Públicas no Instituto Universitário de Lisboa
(ISCTE-IUL), Auditor da Universidade Tecnológica Federal do Paraná (UTFPR).
E-mail: tiagoniwa@gmail.com / Universidade Tecnológica Federal do Paraná - UTFPR:
REITORIA Av. Sete de Setembro, 3165, Rebouças, Curitiba - PR. CEP 80230-901.
\end{abstract}


the study, an empirical component is presented, being a government program of Portugal, denominated "Programa $+\mathrm{e}+\mathrm{i}$ ", that was implemented by the XIX Constitutional Government of Portugal. In this perspective, the article aims to demonstrate the possibility of various combinations and reflections in case studies regarding the state of the art in public policies.

Key words: Public policies, innovation and entrepreneurship, economic policy.

\section{INTRODUÇ̃̃O}

As políticas públicas em inovação e empreendedorismo são construções no campo político para, essencialmente, estimular o desenvolvimento econômico e social. Por isso, as questões relacionadas a essa seara do debate político são denominações de teorias econômicas que visam relacionar a cooperação entre a indústria e a ciência (GUSMÃO, 2002, p. 331), com políticas indutoras direcionadas a esse tema.

Nesse sentido, o presente trabalho visa subsumir os tópicos de inovação e empreendedorismo no âmago das teorias de políticas públicas, considerando as discussões e reflexões aliadas à materialização teórica. Portanto, ilustrativamente, considera-se a política pública portuguesa denominada Programa Estratégico para o Empreendedorismo e a Inovação (Programa $+\mathrm{e}+\mathrm{i}$ ), implementado pelo XIX Governo Constitucional de Portugal, enquanto representação mandatória de política de inovação e empreendedorismo.

Embora seja realizada a ilustração e a breve caracterização do Programa $+\mathrm{e}+\mathrm{i}$, percebe-se que a interiorização conceitual das teorias de políticas públicas pode ser alocada em diversos programas específicos, haja vista o contexto mais amplo das discussões teóricas. Assim, o contexto sócio-histórico e econômico de um Estado, de acepções capitalistas, possui uma orientação para o desenvolvimento da economia, sendo um dos diversos espaços de discussão no ambiente em que se insere, havendo, entre outras e imensuráveis medidas, os pesos e contrapesos das tomadas de decisões políticas.

Portanto, o presente estudo visa demonstrar a contextualização de uma medida de política no campo de inovação e empreendedorismo, representado pelo Programa $+\mathrm{e}+\mathrm{i}$, do Governo de Portugal. A essa contextualização, adotam-se as teorias de políticas públicas da Advocacy Coalition Framework, do racionalismo político e, por fim, do neo-institucionalismo sociológico. 


\section{As Políticas Públicas de Inovação e Empreendedorismo e o Programa $+e+i$, de Portugal}

O Programa $+e+i$ procura instigar o empresariado e a sociedade civil para a inovação e ao estímulo da competitividade da economia nacional, utilizando-se de ações específicas para esses fins. De acordo com a página oficial do Programa $+\mathrm{e}+\mathrm{i}$ (PORTUGAL, [20--?]), os fatores que levaram o Governo de Portugal a instituir o Programa foram, em especial: i) a necessidade de recuperação econômica devido às dificuldades estruturais; ii) a falta de retornos econômicos dos investimentos em Pesquisa e Desenvolvimento (P\&D); iii) a necessidade de soluções de financiamento de novos projetos; iv) a carência de intervenção prioritária em questões de empreendedorismo além do campo da ciência e da pesquisa; v) e as referências da estratégia Europa 2020, e respectiva iniciativa Innovation Union, para o desenvolvimento de políticas em inovação em Portugal para os próximos anos.

No âmbito do Programa Horizonte 2020, da Comissão Europeia, o Programa de Competitividade e Inovação (CIP) e o Instituto Europeu de Inovação e Tecnologia (EIT), em montantes gerais, possuem valores na importância de 80 mil milhões de euros do Programa de Pesquisa e Inovação da União Europeia (UE). Esse investimento visa, na vigência de 2014 a 2020, diminuir a distância entre a inovação e o mercado por meio de três pilares: a excelência da ciência, a liderança industrial e mudanças sociais. (CRISPIM et al., 2014, p. 88).

A materialização de políticas públicas indutoras do desenvolvimento econômico e social, focada no empreendedorismo e na inovação, é uma reação à realidade do aumento do desemprego associado à recessão econômica, sentida, por exemplo, nos países europeus. Tanto que a Organização para a Cooperação e o Desenvolvimento Econômico (OCDE) já predicava a necessidade de políticas em ciência e tecnologia como soluções para o crescimento econômico. (BRANDÃO, 2016, p. 4).

Desta feita, o investimento financeiro e a atenção dada à inovação em um país, especialmente durante a crise econômica, são relevantes para se aprimorar modelos de investigação em inovação, a partir do sucesso e boas práticas internacionais, e, em seguida, desenvolver e aplicar esses modelos em Portugal, relacionando-os ao contexto da União Europeia. (GIBSON; NAQUIN, 2011, p. 1299). 
Assim, acredita-se que o Programa $+\mathrm{e}+\mathrm{i}$, dentro do panorama de políticas econômicas comparadas vigentes, alia as noções de empreendedorismo e inovação, a partir de seus conceitos originários, de critérios consolidados e de interesses dos atores sociais, formando-se um subsistema e coalizão políticos. (SABATIER; WEIBLE, 2007, p. 196).

O empreendedorismo, sobretudo com o ensinamento de Richard Cantillon, no século XVII, e, igualmente a Jean-Baptiste Say, teve originária repercussão em várias áreas do conhecimento. No entanto, foi com Schumpeter que houve maior projeção do empreendedorismo, quando o relacionou à inovação. Dessarte, outros teóricos contribuíram para os temas relacionados ao empreendedorismo, tais como Clark, Higgins, Baumol, Schloss, Leibenstein, Knight, Hoselitz, Casson, Kirzner, entre outros (FILION, 1999, p. 6-7).

A imersão nos complexos temas relacionados ao empreender e ao inovar direciona a uma análise difusa de políticas públicas a partir da transferência de experiências e realizações nesse sentido, observando-se o incrementalismo de medidas prósperas em diversas esferas. Ademais, os processos de análise de políticas públicas podem ser considerados como constantes evoluções, cujo ponto de partida pode estar situado em qualquer momento histórico. (HILL, 2013, p. 155).

No próximo tópico, ademais, averiguam-se o percurso e o desenho da política pública ilustrativa de política de inovação e empreendedorismo, enquanto exórdio deste trabalho: o Programa $+\mathrm{e}+\mathrm{i}$.

\subsection{Análise do desenho e da formulação de Política Pública:}

o Programa $+\mathrm{e}+\mathrm{i}$

As teorias de políticas públicas imiscuem-se em diferentes contextos e processos criativos para explicar os fenômenos de ações no cenário político e social. Com o intuito de realizar uma breve análise da conjuntura empírica e teórico-científica, que caracteriza a implementação do Programa +e+i, do Governo de Portugal, faz-se relevante a análise do desenho da medida de política identificada em etapas.

Portanto, o modelo teórico do processo de análise da medida de política refere-se ao modelo por etapas do ciclo político, identificadas da seguinte maneira: i) Definição do problema; ii) Agenda- 
mento da medida de política pública; iii) Formulação da medida; iv) Concretização da medida (legitimação e implementação); e v) Avaliação e mudança (KRAFT; FURLONG, 2009, p. 72-73).

\subsubsection{Definição do problema}

A medida de política pública do Programa $+e+i$, conforme já identificado em momento pretérito, emergiu da ânsia pela recuperação econômica, pela melhoria dos retornos econômicos dos investimentos em P\&D, soluções para o financiamento de novos projetos, atenção ao tema do empreendedorismo ligado à ciência e à pesquisa, e, por fim, pelas referências à estratégia Europa 2020, e sua iniciativa da Innovation Union, focando-se em políticas de inovação em Portugal (PORTUGAL, [20--?]).

Portanto, enquanto identificação de questão-problema que o Programa $+\mathrm{e}+\mathrm{i}$ visa solucionar, debate-se como ele pode contribuir, efetivamente, para o desenvolvimento e recrudescimento do empreendedorismo e da inovação em Portugal?

\subsubsection{Agendamento da medida de política pública}

O agendamento político para a implementação do Programa $+\mathrm{e}+\mathrm{i}$ possui um histórico de edificação de políticas que pode ser demonstrado pela investigação realizada por Laranja (2012, p. 655), que descreve os fatos e acontecimentos na estrutura portuguesa, bem como os ciclos políticos e suas dimensões.

Inicialmente, o período de 1960 a 1980, pouco antes de Portugal aderir à União Europeia, as políticas de inovação eram essencialmente políticas de investigação e foram considerados como um subconjunto de políticas de desenvolvimento econômico e social mais geral. Esse período é caracterizado principalmente pelos seguintes acontecimentos: problemas de legitimidade da Junta Nacional de Investigação Científica e Tecnológica (JNICT); a criação de estrutura dualista vertical no público de Investigação e Desenvolvimento (I\&D); a ausência de visão compartilhada para o planejamento de longo prazo; e pouca atenção dada à inovação nas empresas. (LARANJA, 2012, p. 660).

No que tange ao período de 1980 a 2000, o nível de análise passa a considerar a adesão de Portugal à UE. O acesso a fundos comunitários estruturais e aos Fundos de Coesão da UE contribuiu 
para fragmentar ainda mais a estrutura institucional envolvida na política de inovação. Em meados de 1990, os esforços do Ministério da Economia, combinados com a criação do Ministério da Ciência e Tecnologia criou uma bipolarização mais forte entre as políticas de investigação e de inovação. No final da década de 1990, houve maior integração de políticas na direção de uma nova abordagem para a governança. (LARANJA, 2012, p. 661).

Por fim, para a compreensão do agendamento da medida de política, o período de 2000 a 2006 apresenta alguns sinais de mudança, tendo em vista o conteúdo do documento de Referência Estratégico Nacional (2000/2006), para os fundos estruturais. Nesse documento, a inovação aparece na política, pela primeira vez, como uma prioridade nacional de enquadramento na economia, na ciência e em outras políticas setoriais. (LARANJA 2012, p. 662). Pode-se destacar a proeminência racionalista (DYE, 2011, p. 15) no aparato em que se considera um fato ou um conjunto de situações como constituidores de valores relevantes para a tomada de decisão política.

Em 2001, a iniciativa Proinov, conduzida centralmente pela Presidência do Conselho de Ministros, apresentou um conjunto mais vasto de políticas que envolvem a ciência, a educação, a sociedade da informação e a inovação. No entanto, com o advento de um novo governo em 2002, o Proinov chegou ao fim pouco depois de seu lançamento, sem ter tido tempo para demonstrar os potenciais benefícios de uma nova governança horizontal. Pode-se afirmar que, nesse período, a política de inovação em Portugal começou a ser tratado como uma política guarda-chuva para outras políticas setoriais. (LARANJA, 2012, p. 662).

\subsubsection{Formulação da medida}

A formulação da medida da política pública está circunscrita na realidade das atuais economias em incentivar a inovação para com o empreendedorismo e à indústria, enquanto importante característica para aumentar a competitividade e melhorar a economia nacional. (PORTUGAL, 2011b).

O Programa +e+i é um Programa do XIX Governo Constitucional, que, portanto, aponta o empreendedorismo e a inovação como objetivos prioritários para o desenvolvimento. (PORTUGAL, [20--?]). 
Essa medida de política foi oficializada pela Resolução do Conselho de Ministros n. ${ }^{\circ}$ 54, publicada no Diário da República em 16 de dezembro de 2011, que designa ao Ministro da Economia e do Emprego a implementação do Programa $+\mathrm{e}+\mathrm{i}$, por delegação do Primeiro Ministro Pedro Passos Coelho. (PORTUGAL, 2011a; 2011b).

\subsubsection{Concretização da medida}

O Programa $+\mathrm{e}+\mathrm{i}$, implementado pela Resolução do Conselho de Ministros n. ${ }^{\circ}$ 54, de 16 de dezembro de 2011, assenta-se em quatro pilares fundamentais, a saber: i) no alargamento das competências da população, incluindo a população jovem e a socialmente desprotegida, das empresas e da Administração Pública; ii) na dinamização da inovação, designadamente ao nível de produto, processos e tecnologia, por forma a promover a competitividade das empresas portuguesas; iii) no estímulo ao empreendedorismo, promovendo um contexto favorável ao surgimento de projetos empreendedores e ao seu sucesso; iv) e na promoção destes objetivos através de adequados instrumentos de financiamento, com uma repartição justa dos fundos disponíveis pelas iniciativas de excelência. (PORTUGAL, 2011a).

As ações concretizadas do Programa $+\mathrm{e}+\mathrm{i}$ são identificadas com as seguintes denominações (PORTUGAL, [20--?]): i) Passaporte para o Empreendedorismo; ii) Rede Nacional de Mentores; iii) Programa de Ignição; iv) Agenda Portugal Digital; v) Programa PME Digital (para micro, pequenas e médias empresas); vi) Guia Prático do Empreendedor; e vii) Selo $+\mathrm{e}+\mathrm{i}$. Todavia, considerando que a trajetória deste trabalho visa refletir acerca das teorias de políticas públicas envoltas na seara da inovação e do empreendedorismo, o detalhamento de cada ação dessa política torna-se, por ora, desnecessário.

\subsubsection{Avaliação e mudança}

A transição das décadas de 1970 e 1980 preparou os parâmetros de políticas tecnológicas para a década de 1990, ocasionando um ciclo político de imperativos tecnológicos da política científica, sob a égide de culturas econômicas e burocráticas. (BRANDÃO, 2016, p. 14-15). Desta feita, a própria estruturação neo-institucionalista sociológica faz-se presente quando se destacam o recrudescimento 
de estruturas sociais que evidenciam a forma de algo socialmente constituído. (HALL; TAYLOR, 2003, p. 211).

Vale dizer, ainda, que a inevitável descontinuidade das medidas políticas de incentivo e a redução nos investimentos em educação, I\&D e inovação, em tempos recentes, podem levar a um risco de dano irreversível para o crescimento e modernização do conhecimento. (LOPES, 2014, p. 56-57).

Ante o exposto, acredita-se que o processo de análise do desenho de uma medida de política contribui para a parametrização material e a consecutiva subsunção desse objeto às teorias de políticas públicas, demonstradas e concatenadas no próximo capítulo.

\section{A POLÍTICA PÚBLICA DE INOVAÇ̃̃O E EMPREENDEDORISMO À LUZ DOS MODELOS TEÓRICOS}

A concepção de uma determinada medida de política pode ser analisada frente aos diversos referenciais teóricos existentes no estado da arte de políticas públicas. Contudo, para fins de análise e reflexão, este trabalho dirige-se a três teorias distintas, sendo as seguintes: advocacy coalition framework (SABATIER; WEIBLE, 2007, p. 189), racionalismo político (PARSONS, 1996, p. 272), e o neo-institucionalismo sociológico. (HALL; TAYLOR, 2003, p. 207; MARCH; OLSEN, 2008, p. 126).

\subsection{Advocacy Coalition Framework: a coalizão política no debate sobre inovação e empreendedorismo}

Quando se discute uma seara específica do conhecimento e do campo político, verifica-se que, a partir de desenhos teóricos das diversas ciências existentes, é possível realizar a construção (ou desconstrução) de como foi desenhada uma política pública. Pensando nessa questão, acredita-se que a política pública que trata de assuntos relacionados à inovação e ao empreendedorismo possui particularidades muitas vezes comuns entre países que adotam teorias econômicas vigentes. Vale dizer, sobretudo, sobre a maior interação entre a ciência e a indústria (GUSMÃO, 2002, p. 331), e a relação da inovação com o empreendedorismo.

Revela-se que a arena política que se forma a despeito da temática da inovação e do empreendedorismo tem como caracte- 
rística a formação de um grupo de interesse que procura melhorar as condições econômicas e sociais da sociedade. Vale dizer que há a formação de um subsistema de organização política que defende a realização de políticas públicas voltadas a essa questão. E esses subsistemas, que buscam, em um embate de forças, conquistar espaço na arena política, são compostos por uma série de coalizões de defesa, que se identificam uns dos outros em razão de suas crenças e recursos, compreendendo-se, portanto, a Advocacy Coalition Framework. (PARSONS, 1996, p. 197).

A Advocacy Coalition Framework foi originariamente publicada como um tema de um Simpósio de Ciência Política, sendo revisada em 1993 enquanto um resultado de seis estudos de caso, solicitados pelos autores Sabatier e Jenkins-Smith. A pesquisa inicial referiu-se a questões de energia norte-americana e políticas ambientais, que são os campos de expertise dos autores. (SABATIER; WEIBLE, 2007, p. 189).

Assim, essa coalizão política argumenta que os atores políticos procuram se aliar a indivíduos que possuem crenças políticas similares dentre legisladores, órgãos oficiais, grupos de interesse, lideranças, juízes, investigadores e intelectuais dos vários níveis de governo. E se o envolvimento a esses indivíduos ocorrer de forma não-trivial, isto é, reunindo esforços para se alcançar objetivos políticos semelhantes, forma-se uma Advocacy Coalition. (SABATIER; WEIBLE, 2007, p. 196).

Importa dizer que a formulação de especificidade política, visando atender a determinados interesses, conjuga forças a outros atores, e, ao mesmo tempo, deve enfrentar outras coalizões dentro do debate político para que certa ação possa ser implementada.

Pela Figura 1, constata-se o diagrama da Advocacy Coalition Framework, cujo desenho é possível subsumir as políticas de inovação e de empreendedorismo, visto que se trata de um debate subsistêmico, com atores políticos delineados, objeto desenvolvido e segmentado nas discussões socioeconômicas, e expectativa de mudanças no cenário e condições econômicas e sociais. 
Figura 1 - Diagrama do Advocacy Coalition Framework

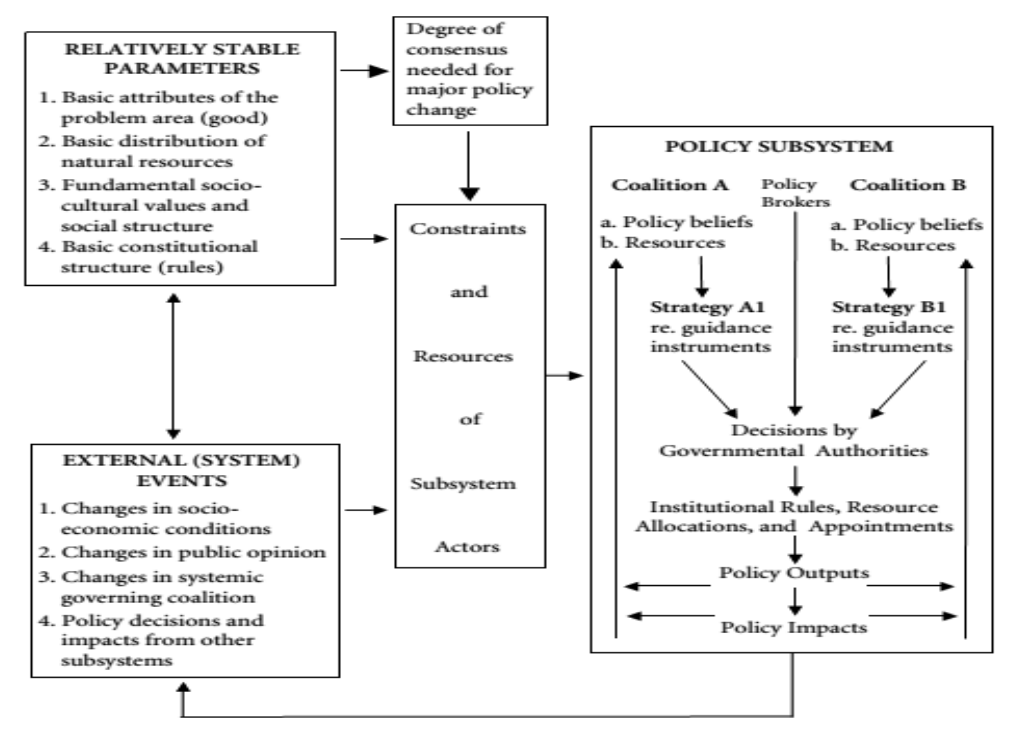

Fonte: SABATIER, P. A. Theories of the Policy Process. Colorado: Westview Press, 2007. p. 191.

Para Parsons (1996, p. 85), a Advocacy Coalition Framework pode ser compreendida como uma meso-análise de política pública, encontrando-se na transição entre a definição do problema de análise e o agendamento de políticas, com a tomada de decisões e a implementação dos processos.

Enquanto processo natural de contenda política, enquanto espaço limitado para implementação de políticas públicas, verifica-se que um subsistema político apresenta uma diversidade de Advocacy Coalitions, que competem por influências ou pelo processo de tomada de decisões. Ademais, as coalizões políticas aprendem com a observação de mudanças e feedbacks enquanto estratégias de orientação de coligações, compreensão do mundo e dos objetivos políticos. (PARSONS, 1996, p. 198).

Portanto, o subsistema político interage com outros subsistemas, bem como com demais recursos amplos de ordem social, jurídico, econômico e institucional, sendo os parâmetros do sistema definidos pelos conjuntos de forças da estabilidade e da mudança. (PARSONS, 1996, p. 198). 
Por essa razão, dentro da análise de política que agrega as questões de empreendedorismo e inovação, havendo a coligação de interesses entre o empresariado e a indústria, com instituições de ensino superior, de $\mathrm{P} \& \mathrm{D}$, acredita-se que a coalizão ocorre por meio do embate de crenças e de objetivos que podem diferir no tempo e espaço. Ademais, outras advocacias de coalizões políticas podem interferir ou mesmo inibir a emersão da medida de política, prejudicando o agendamento e respectiva concretização da política.

Por fim, a perspectiva de interação entre o empreendedorismo e a inovação pode gerar conflitos, quiçá, ideológicos por parte de profissionais de ensino e pesquisa, quando se pretende interagir a ciência com a indústria. Contudo, a essa nova realidade, e partindo da teoria econômica vigente de uma economia baseada no conhecimento (CASTELLS, 2006, p. 119), faz-se natural, embora contestável, o convencimento das coalizões políticas dessa realidade.

\subsection{Racionalismo Político: o contexto sociológico e econômico}

O contexto teórico do racionalismo faz-se importante, tendo em vista que se trata de uma fonte literária em que se averigua o interesse de economistas pelas questões organizacionais, bem como o interesse de sociólogos por assuntos econômicos. (PARSONS, 1996, p. 271).

Parsons (1996, p. 245) trata o racionalismo e o institucionalismo no capítulo que compreende a análise da tomada de decisões de políticas públicas, sendo esta encarada como processos de escolhas e decisões que envolvem um ou vários pontos no tempo e espaço, de acordo com o arranjo valorativo e objetivos traçados pelos formuladores de política (policy makers).

Portanto, a racionalidade utilizada em políticas públicas tem a raiz na construção do homem da economia, podendo ser compreendido como um indivíduo que calcula seus próprios interesses. Em tomada de decisões, o indivíduo realiza suas escolhas pela máxima aquisição de informações necessárias, comparando a informação em diferentes visões, e, então, seleciona a opção que permitirá alcançar seus objetivos e interesses. E num segundo contexto da teoria racionalista trata do estudo das organizações, de influência weberiana. (PARSONS, 1996, p. 272). 
Os modelos de tomada de decisões argumentam que o desejo para se entender o real desejo global, deve-se considerar até que ponto a decisão é resultado de processos racionais. $\mathrm{O}$ modelo weberiano de racionalismo imperativo na tomada de decisões constitui o ponto de partida para a análise racionalista de políticas públicas. E a literatura busca criticar o tipo ideal em detrimento da realidade empírica da tomada de decisões, bem como as limitações da racionalidade na tomada de decisões dos indivíduos. (PARSONS, 1996, p. 273).

O modelo da firma, predominante na teoria econômica neoclássica, possui a visão da firma como uma organização, cujos processos de tomadas de decisões são motivados pela busca racional do lucro, e pelo indivíduo que age por interesses próprios de acordo com o seu perfeito conhecimento. (PARSONS, 1996, p. 299).

Dye (2011, p. 15) destaca que a política racional é aquela que busca o máximo ganho social; significa que o governo deve realizar políticas, cujos ganhos para a sociedade sejam superiores aos seus custos, devendo-se evitar políticas, cujos custos excedam os benefícios. Por isso, o autor exalta duas características importantes: a) que não se devem implementar políticas públicas quando seus custos sejam maiores que seus benefícios; e b) se houver oportunidade de escolhas entre diferentes políticas, deve-se optar pela que oferece melhor custo-benefício.

O racionalismo, ainda, leva em consideração todos os valores sociais, políticos e econômicos envolvidos para a formulação da política pública, não apenas no sentido do custo monetário. Por isso, no contexto racionalista, os policy makers devem: a) conhecer todas as preferências valorativas da sociedade e seus respectivos pesos; b) conhecer todas as alternativas políticas disponíveis; c) conhecer todas as consequências de cada alternativa de política; d) calcular o custo-benefício para cada alternativa de política; e e) selecionar a alternativa de medida de política mais vantajosa. (DYE, 2011, p. 15). Torna-se latente, no entanto, que o engessamento de uma narrativa de construção política, nesses parâmetros racionalistas, pode parecer difícil de realizar.

Kingdon (1995) denomina a tomada de decisões racionalista como, também, compreensiva. Todavia, realiza duras críticas a esse modelo, tendo em vista as limitações das pessoas no processamento de informações. $\mathrm{O}$ autor destaca que os indivíduos são incapazes de 
organizar várias alternativas, e mantê-las simultaneamente na cabeça, comparando-as sistematicamente. Ainda, os indivíduos não têm claramente suas metas e objetivos bem definidos; o que pode ser contraprodutiva a criação de uma coalizão de alternativas e argumentos para convencer outras pessoas a adotarem determinada política. Por fim, ele afirma que os estudos de casos podem parecer inseguros ou confusos para os racionalistas, pois não são bem definidos, e nem de processamento ordenado. (KINGDON, 1995, p. 78).

Portanto, a construção de uma política pública específica para a inovação e o empreendedorismo compreende no debate público acerca das vantagens e desvantagens de modelos, de acordo com teorias econômicas vigentes. Desta feita, acredita-se que a formulação de políticas públicas dessa natureza deve realizar a análise sistemática (com metas e objetivos bem definidos) a fim de se construir medidas de políticas que tragam benefícios econômicos e sociais, embora o marco teórico do racionalismo político possa assinalar demasiada rigidez.

\subsection{O Neo-Institucionalismo Sociológico na discussão de Políticas Públicas}

O estudo das instituições leva em consideração a complexidade multidisciplinar, os vários níveis de análise envolvidos, as influências do meio e os fenômenos culturais, razão pela qual Ostrom (2007, p. 25) realiza a análise institucional em três especificidades: i) quadros; ii) teorias; e iii) modelos. O autor relata que cada especificidade proporciona diferentes graus de análise relacionados a um problema em particular.

O desenvolvimento e a utilização de um quadro geral ajudam a identificar os elementos e as relações entre eles, que se deve considerar para a análise institucional. Já o desenvolvimento e a utilização de teorias permite ao analista especificar quais elementos do quadro são particularmente relevantes para certos tipos de perguntas, bem como para se fazer suposições gerais de trabalho sobre esses elementos. E, por fim, o desenvolvimento e a utilização de modelos realizam suposições precisas sobre um limitado conjunto de parâmetros e variáveis. (OSTROM, 2007, p. 25-26).

Tradicionalmente, a ciência política define seus estudos sobre as instituições governamentais, sendo as atividades políticas geralmente realizadas em volta de instituições de governo em particular 
(Congresso, Presidência, Tribunais, Estados, Municípios, burocracias e outros). As Políticas Públicas são autoritariamente determinadas, implementadas e forçadas por essas instituições. De acordo com Dye (2011, p. 12), as instituições governamentais oferecem três características distintas: i) legitimidade, pois são tratadas como obrigações legais para cumprimento dos cidadãos; ii) universalidade, pois as políticas se estendem a toda sociedade, ou a um todo de um grupo ou organizações; e iii) coercitividade, pois o Estado pode usar de sanções para controlar o cumprimento das políticas implementadas.

Esse neo-institucionalismo, de acordo com March e Olsen (2008, p. 126-127), pode ser apresentado e debatido sob a óptica epistemológica de profunda relevância para se depreender as Ciências Sociais. Porém, os autores acreditam que é mais interessante conceituá-lo como um conjunto limitado de desafios ao pensamento teórico contemporâneo, assim como enquanto um pequeno conjunto de ideias relativamente técnico de interesse para os estudiosos profissionais da vida política.

Essas ideias, segundo os autores, diminuem a dependência do Estado politicamente organizado se comparado à sociedade, em prol de uma interdependência institucional das áreas sociais e políticas relativamente autônomas; elas minimizam a simples primazia de microprocessos e histórias eficientes em favor de processos relativamente complexos e da ineficiência histórica; elas diminuem as metáforas da escolha e os resultados inerentes em favor de outras lógicas de ação, assim como da centralidade do significado e da ação simbólica. (MARCH; OLSEN, 2008, p. 126-127).

Assim, o neo-institucionalismo, juntamente com a maior parte das investigações sobre preferências, idealiza que, nas questões políticas, assim como em outras áreas da vida, as preferências e os significados desenvolvem-se em razão da combinação da educação, do doutrinamento e da experiência. ( MARCH; OLSEN, 2008, p. 128).

Portanto, o termo neo-institucionalismo é comumente utilizado na ciência política para designar uma visão teórica que chama muita atenção, mas também críticas. Há, todavia, grande discussão no que tange ao sentido preciso do termo, que decorre desde as diferenças quanto a outros procedimentos, quanto ao tipo de questões e soluções que suscita. Ademais, sabe-se que o neo-institucionalismo não possui uma corrente de pensamento unificada, havendo diversos 
debates a respeito. Por isso, a partir da década de 1980, apareceram, ao menos, três métodos de análise distintos no que concerne ao denominado neo-institucionalismo, sendo designados, por Hall e Taylor (2003, p. 193), como as escolas do institucionalismo históri$\mathrm{co}$, do institucionalismo da escolha racional, e do institucionalismo sociológico.

O nível de análise que se remete a presente discussão de formulação de políticas, por suscitar questões de ordem construída em determinada realidade socio-histórica, é o institucionalismo sociológico, que possui origem no quadro da teoria das organizações. (HALL; TAYLOR, 2003, p. 207).

Essa escola de pensamento tem origem no fim da década de 1970, ocasião em que os sociólogos realizaram a discussão e o embate entre a esfera do mundo social (de racionalidade do tipo burocrática) e as esferas de influência de diversas ações relacionadas à cultura. (HALL; TAYLOR, 2003, p. 207).

Hall e Taylor (2003) afirmam que, desde Max Weber, vários sociólogos consideram que as estruturas burocráticas da modernidade são frutos de grande esforço para a elaboração de estruturas mais eficazes e destinadas a atender tarefas formais. Acreditam que as formas de organização dessas estruturas eram muito similares, tendo em vista a racionalidade e as características para fazer cumprir as tarefas necessárias. Portanto, a cultura era compreendida como algo bastante diverso. (HALL; TAYLOR, 2003, p. 207).

Os sociólogos alinhados a essa linha institucionalista, comumente, optam por resolver questões atinentes às escolhas organizacionais quanto à forma, símbolos institucionais e procedimentos, e como essas características são difundidas. Assim, os estudiosos procuram explicar, por exemplo, as semelhanças de questões formais ou práticas, entre os Ministérios da Educação no mundo, independentemente das suas diferenças contextuais; ou mesmo dentre empresas de setores industriais diversos, independentemente dos produtos fabricados. (HALL; TAYLOR, 2003, p. 208).

Essa realidade, acredita-se, pode ser aplicável ao debate da inovação e do empreendedorismo, quando se destaca, inclusive, certo mimetismo de formulação de políticas públicas entre países, sendo uma padronização de efeitos globais de estruturas, culturas e valores constituídos e consolidados. 
Portanto, significa que as organizações adotam formas e práticas institucionais próprias coadunadas a um campo reconhecido em um ambiente cultural mais amplo. Contudo, os estudiosos sustentam que as instituições, muitas vezes, adotam práticas que condizem menos com a eficiência institucional, e mais em prol da legitimidade social. Por isso, os teóricos afirmam que as escolhas dos indivíduos, consideradas como ação racional, em verdade, é ele mesmo um produto socialmente constituído. (HALL; TAYLOR, 2003, p. 211).

\section{CONCLUSÃO}

As teorias de políticas públicas possuem diferentes perspectivas e características que buscam compreender fenômenos sociopolíticos existentes na sociedade. Por esta feita, o presente trabalho visa passear dentre distintos marcos teóricos a partir de um pequeno ponto, dentre uma imensidão de possíveis casos de estudo. Assim, procura-se refletir sobre a subsunção de acontecimentos empíricos em torno da consolidação de teorias e investigações realizadas.

$\mathrm{O}$ exercício de relacionar os processos teóricos à empiria, ou vice-versa, é um meio de selecionar, dentro de um vasto número de possibilidades no plano das ideias, um evento de consciência que se transmuta em saber e ciência. Por isso, a seleção de compreensões teóricas diversas também pode ocasionar na inevitável comparabilidade entre uma e outra escolha, haja vista a distinção semântica e aparente de cada uma delas.

De qualquer sorte, a jornada pelo estado da arte em teorias de políticas públicas, assim como se acredita ser em outras áreas do saber, é um desafio no que concerne à adequabilidade teórica em um determinado espaço, tempo e sociedade. Assim, as políticas destinadas à promoção da inovação e do empreendedorismo são realidades de teorias que veiculam, dentre outros assuntos, a interação e a cooperação entre a indústria e a ciência.

Desse modo, dentro da perspectiva da coalizão política, há a formação de um subsistema valorativo que defende a ideia da inovação e do empreendedorismo para o desenvolvimento econômico e social. Outrossim, o agendamento da política e as respectivas formulações e concretizações de medidas de políticas são, de certa forma, idealizadas a partir de uma racionalidade política, embora com suas limitações evidentes. E, por fim, o neo-institucionalismo sociológico resolve por ministrar a condição das organizações na sua capacidade 
de formular políticas e atender aos interesses dos atores políticos, conforme os padrões estabelecidos.

E dentro dessa análise resultante de passeios teórico-científi$\cos$ da proposta realizada, julga-se essencial a reflexão sobre outros e incontáveis fatos empíricos e teóricos que podem resultar em outros exames no estado da arte em políticas públicas.

\section{REFERÊNCIAS}

BRANDÃO, T. Shaping portuguese science policy for the european horizon: the discourses of technological change. Technological Forecasting and Social Change: an internacional journal, [S. 1.], v. 113, part. b, p. 168-184, dec. 2016. Disponível em: <http://linkinghub. elsevier.com/retrieve/pii/S0040162515002760>. Acesso em: 22 out. 2015.

CASTELLS, M. A sociedade em rede. 9. ed. São Paulo: Paz e Terra, 2006.

CRISPIM, J. et al. Smart grids in the eu with smart regulation: experiences from the uk, italy and portugal. Utilities Policy, East Lansing, v. 31, p. 85-93, 2014. Disponível em: $<$ http://www. sciencedirect.com/science/article/pii/S0957178714000678>. Acesso em: 23 out. 2015.

DYE, T. R. Understanding Public Policy. 13. ed. Boston: Longman, 2011.

FILION, L. J. Empreendedorismo: empreendedores e proprietáriosgerentes de pequenos negócios. Revista de Administração, São Paulo, v. 34, n. 2, p. 5-28, abr./jun. 1999.

GIBSON, D. V.; NAQUIN, H. Investing in innovation to enable global competitiveness: the case of portugal. Technological Forecasting and Social Change: an internacional journal, [S. 1.], v. 78, n. 8, p. 1299-1309, oct. 2011. Disponível em: <http://dx.doi.org/10.1016/j. techfore.2011.04.004>. Acesso em: 23 out. 2015.

GUSMÃO, R. Práticas e políticas internacionais de colaboração ciência-indústria. Revista Brasileira de Inovação, Campinas, SP, v. 1, n. 2, p. 327-360, 2002. Disponível em: <http://plutao.ige.unicamp.br/ ojs/index.php/rbi/article/viewArticle/247>. Acesso em: 1 nov. 2015.

HALL, P. A.; TAYLOR, R. C. R. As três versões do neoinstitucionalismo. Lua Nova: Revista de Cultura e Política, São Paulo, v. 58, n. 58, p. 193-223, 2003. Disponível em: <http://www.scielo.br/ 
scielo.php?script=sci_arttext\&pid=S0102-64452003000100010\&lng= pt\&nrm=iso\&tlng=pt $>$. Acesso em: 21 out. 2015.

HILL, M. The Public Policy Process. 6. ed. New York: Routledge, 2013.

KINGDON, J. W. Agendas, alternatives, and public policies. 2. ed. New York: Longman, 1995.

KRAFT, M. E.; FURLONG, S. R. Public Policy: Politics, Analysis, and Alternatives. 3. ed. Washington, D.C.: CQPress, 2009.

LARANJA, M. Network governance of innovation policies: the technological plan in portugal. Science and Public Policy, Oxford, v. 39, n. 5, p. 655-668, oct. 2012. Disponível em: <http://spp. oxfordjournals.org/cgi/doi/10.1093/scipol/scs043>. Acesso em: 21 out. 2015.

LOPES, M. M. S. C. The development of knowledge in Portugal: a slow and unsustainable progress. IUP Journal of Knowledge Management, [S. 1.], v. 12, n. 3, p. 42-61, 2014.

MARCH, J. G.; OLSEN, J. P. Neo-institucionalismo: fatores organizacionais na vida política. Revista de Sociologia e Política, Curitiba, v. 16, n. 31, p. 121-142, nov. 2008.

OSTROM, E. Institutional Rational Choice: An Assessment of the Institutional Analysis and Development Framework. In: SABATIER, P. A. (Ed.). Theories of the Policy Process. Boulder: Westview Press, 2007. p. 21-64.

PARSONS, W. Public policy: an introduction to the theory and practice of policy analysis. Cheltenham: Edward Elgar, 1996.

PORTUGAL. Declaração de Rectificação n ${ }^{\circ} 35$, de 21 de dezembro de 2011. Rectifica a Resolução do Conselho de Ministros n. ${ }^{\circ}$ 54/2011, de 16 de dezembro, que aprova o Programa Estratégico para o Empreendedorismo e a Inovação, publicada no Diário da República, 1. ${ }^{\mathrm{a}}$ série, n. $^{\circ}$ 240, de 16 de dezembro de 2011. Diário da República, Lisboa, $1^{\mathrm{a}}$ série, $\mathrm{n}^{\mathrm{o}}$ 243, p. 5351-5354, $21 \mathrm{dez} .2011 \mathrm{a}$.

. Resolução do Conselho de Ministros no 54, de 16

de dezembro de 2011. Aprova o Programa Estratégico para o Empreendedorismo e a Inovação. Diário da República, Lisboa, $1^{\text {a }}$ série, $\mathrm{n}^{\circ}$ 240, p. 5.315-5316, 12 dez. 2011b.

. Programa Estratégico para o Empreendedorismo e a Inovação (Programa $+\mathrm{e}+\mathrm{i})$. Lisboa, [20--?]. Disponível em: <http://www.ei.gov. pt/index/>. Acesso em: 1 nov. 2015. 
INOVAÇÃO E EMPREENDEDORISMO À LUZ DE TEORIAS DE POLÍTICAS PÚBLICAS

SABATIER, P. A. Theories of the Policy Process. Colorado: Westview Press, 2007.

; WEIBLE, C. M. The Advocacy Coalition Framework:

Innovations and Clarifications. In: SABATIER, P. A. (Ed.). Theories of the Policy Process. Boulder: Westview Press, 2007. p. 189-222. 
